\title{
Insurance and climate change
}

Submitted to Brisman, A \& South, N Eds.

Routledge International Handbook of Green Criminology (Routledge International Handbooks) 26 June 2018Liam Phelan, Cameron Holley, Clifford Shearing and Louise du Toit

'... risk will no longer grow as a linear function ... Instead risks will multiply exponentially and with gathering speed ... As far as the insurance industry is concerned, this development calls for immediate action' (Kaufmann 1990, no page number).

'Underwriting climate destroying coal projects [in] this day and age exposes the climate rhetoric of most major insurance companies as hypocritical' (Bosshard 2017, 7).

\section{Insurers as shapers of climate risk}

This chapter explores the role of the global insurance industry in creating, adapting to, and mitigating climate risk. Since the early 1990s, insurance has been characterised repeatedly as the industry with the most to lose in a climate-changed world, and therefore the business sector most likely to take a lead in mitigation (Gelbspan 1998; Leggett 1993; Sachs et al. 1998). This characterisation of the industry as particularly vulnerable to climate change impacts has persisted (Pinkse and Kolk 2009, 93; Johannsdottir et al. 2014, 88). Yet in the main, where insurers have responded to climate change, responses have emphasised adaptive and some weak, rather than strong, mitigative measures (Phelan et al. 2011).

The insurance industry has been described as 'society's primary financial risk manager' (Hecht 2008, 1959). Given the magnitude of the risks that climate change (and many other environmental harms) present to human societies (Beck 1992), the ways insurers respond to climate change, including through shaping others' behaviour, are important. Insurers are significant regulators at both individual and institutional levels - something that the United 
Nations Environment Programme's (UNEP) Finance Initiative recognises (see, for example, UNEP-FI 2009; see also UNEP-FI 2011).

Since 1988, 100 companies have been responsible for $71 \%$ of global industrial greenhouse gas emissions (Griffin 2017, 8). In recognising the significance of insurance, this chapter is premised on a view that as well as creating harms, the private sector has a role in addressing environmental harms and delivering public goods, like safety and environmental security (Harrington and Shearing 2017; Shearing 2015). This approach builds on a growing trend in criminology and policing scholarship to look beyond state visions of governance (Bayley and Shearing, 2001) toward other providers of environmental security (Holley, Gunningham and Shearing 2012; Holley and Shearing 2016). This approach, however, has sometimes been at odds with green criminology's long history of critical narratives and resistance against corporate (and state) activities that harm humans and the environment (Walters 2010, 320).

It is within this broader debate that the insurance industry has become a growing site of interest for criminologists focused on climate change harms and the many challenges posed by the age of the Anthropocene (Holley and Shearing 2017) — an age in which humans have been identified as 'geological agents' (Chakrabarty 2009). In today's risk society (Beck 1992), the insurance industry has been recognised as imposing new 'templates of control' on crime (Ericson and Carriere 1994), and, as O’Malley (2017) has argued recently, insurance was just as relevant to the nineteenth century proposal by Jeremy Bentham to place a monetary value on harms and to focus 'criminal' justice on financial compensation. Others, such as Nel, Shearing and Reyers (2011), have also argued that insurance can positively shape societal behaviour, such as encouraging communities to actively manage and restore the ecological buffering capacity of landscapes, which can significantly reduce current and future risks associated with climate change (see also Herbstein et al. 2013). 
Not everyone agrees that the regulatory power of the insurance industry will significantly reduce its clients' misbehaviour (South 2015, 273), however. For example, Hall and Farrall (2013, 126-127) argue that climate risks will increase the likely costs of insurance coverage, and thus weaken trust in the insurance sector. This, it is argued, will lead customers to commit more economic crimes, such as over-claiming losses and fraud (Hall and Farrall 2013, 126127). Furthermore, South $(2015,270)$ has cautioned that insurance can 'encourage "deresponsibilization" and hence risk-taking and anthropogenic damage to the environment'.

Examining these and other debates will require many more empirical studies to identify the conditions (e.g., the levels of awareness, motivations and pathways for institutional change (Petersen, Shearing and Nel 2015; Holley and Lecavalier 2017)) and consequences of insurance acting within broad networks of state and non-state nodes to address climate change (see, e.g., Honig et al. 2015; Shearing 2015). This chapter uses a desktop study to examine the insurance industry's potential as a 'fulcrum institution' (Shearing 2015) that can influence others to prevent and address environmental harms from climate change (Nel, Shearing and Reyers 2011). As this chapter will demonstrate, given insurance's central economic role, the relationship between insurers and climate change is complicated and conflicted (Herbstein 2015).

In the next section of this chapter, we explain how insurers are strongly implicated in creating climate change and attendant climate risk in the period since industrialisation through facilitating the accelerating fossil fuel-based economic development and growth that causes climate change; this is the dominant dimension in insurers' relationship with climate change. Currently, and despite good and long-established understanding of climate change and associated risks (IPCC 2013; Wuebbles et al. 2017), insurers continue to facilitate increasing 
fossil fuel-based economic growth and resultant greenhouse gas emissions that drive climate change.

In section three of this chapter, we review insurers' responses over the past decade to increasing climate risk. Responses have been largely adaptive, and aimed at increasing insurers' capacity to accommodate the climate risks faced by their policyholders. Some responses have been 'weakly mitigative', meaning that they provide for some mitigation, but on a very limited scale, and largely as side effects of initiatives unrelated to climate change (Phelan et al. 2011). In marked contrast, a very limited number of recent 'divest and decline' actions by insurance industry actors can be described as 'strongly mitigative', noted in section four. Section five concludes the chapter with some remarks on the prospects for further strong mitigation action from insurers on climate change and their role as governors of security beyond the state (Ericson and Carriere 1994).

\section{Insurers' historical and continuing role in creating climate risks}

Insurance has a long history (Trenerry 1926) playing a central role in facilitating the conduct and expansion of trade and other economic activity: '[s]hips do not sail and capital is not deployed abroad without adequate insurance protection' (Pfeffer and Klock 1974, 272). Historians trace the beginnings of insurance's role in facilitating trade in monetary economies as far back as circa $3000 \mathrm{BC}$ in China (Fink 2011), and insurance provisions in the Code of Hammurabi from $2250 \mathrm{BC}$ in Babylon (Pfeffer and Klock 1974, 27). The literature on historical aspects of insurance focuses on several key themes, primarily the functions of transferring risk (e.g., Pfeffer and Klock 1974; Melone 1964; Clark 1999) and pooling risk (e.g. Kulp and Hall 1968, 10).

Shifting focus forward to the Industrial Revolution and climate change's origin, insurance was already a long-established facilitator of economic activity and expansion. 
Supple (1984) argues that insurance, understood as an economic and financial mechanism, is 'directly associated with . . modernisation of economic and social arrangements, and, therefore, with the growth of the British economy from the late eighteenth century' (Supple 1984, 3).

Shifting perspective forward again to the contemporary period, insurance is described 'as a business, a legal institution, a technique for averaging loss, and an instrument of social planning, [with] many faces and forms, which continue to confound simple classificatory schemes' (Denenberg 1963, 323). Contemporary Western society is deeply dependent on insurance such that insurance is considered central to modern societies and economies. Lengwiler (2003) goes as far as to describe contemporary Western society as the insurance society', with the creation of welfare states (Harvey 2005) serving as the most comprehensive example of public policy reliance on insurance (Lengwiler 2003).

The dependence of fossil fuel-based economic activity on insurance is evident in the sheer size of the insurance industry, the world's largest by revenue-larger than defence, electricity generation, oil or pharmaceutical industries (Mills 2012). Revenue earned from premiums alone amounted to US\$4.7 trillion in 2016 (Swiss Re Institute 2017). In addition, insurance companies earn income from investments, which in 2009 was estimated at around US\$1 trillion (Mills 2009). In 2014, insurers held US\$29 trillion under management, including investments of third parties, which represent about one-third of global assets under management (Bosshard 2017, 8). Insurance provided through markets is complemented by social forms of insurance, including public expenditure in welfare states on health, unemployment benefits and age and disability pensions. In combination, commercial and social insurance provision has been estimated to be at least $15 \%$ of the value of the global economy (Phelan et al. 2011). 
Climate change, as noted above and elsewhere (e.g., Bradshaw and Kramer, this volume) is caused by fossil fuel-dependent economic activity, and is not solely the responsibility of the insurance industry. Insurers have and continue to play a critical enabling role in the expansion of the fossil fuel-based economic activity causing climate change and attendant climate risks (South 2015), however. As such, insurers - both historically and currently-are implicated strongly in the creation of climate change and climate risk.

Yet, as for all of humanity, the insurance industry is not immune to the impact of anthropogenic climate change. At present, insurers are able to manage financial risk in the global economy while the Earth system remains in a familiar, albeit precarious state (Rockström et al. 2009). This is because familiar, stable conditions and past experience provide a reasonable guide to the future, enabling insurers to calculate and price risks (Phelan, Henderson-Sellers and Taplin 2011). A changing climate renders the Earth system unstable and characterised by unpredictable change (Schneider 2004).

On a timescale of interest to humans and our societies, the sum of climate changerelated feedbacks in the Earth system is positive, i.e., climate change leads to feedbacks that amplify rather than dampen changes in the climate (Allen and Frame 2007; Roe and Baker 2007; see Meadows 1999, for a discussion of feedback in complex systems). Net positive feedback leads to further increases in warming that push the Earth system further away from a familiar stable state to an alternate state which, whether stable or unstable, is unfamiliar. The non-linear quality of the change means the rate of the shift is continually increasing and in practice, observed rates of climate change are repeatedly underestimated (Phelan, HendersonSellers and Taplin 2010). In addition, Earth systems thresholds result in rates of change that are uneven and unpredictable. Conventional predictive models and 'ever-finer scale risk assessments' thus have limited power in the context of non-linear change (UNEP-FI 2011, 10). Over time, increasing unpredictability will tend to undermine the viability of the insurance 
industry (Phelan, Henderson-Sellers and Taplin 2010). The concept of 'the trillionth tonne' (see Allen et al. 2009) makes plain the importance of reducing quickly anthropogenic emissions, as does the defining of the Anthropocene and the challenges this poses for the future of environmental security (Shearing, Harrington and Holley, forthcoming).

\section{Insurers' adaptation to climate risk}

In 1973, Munich Re, one of the world's largest reinsurers (key actors in the industry who assume some of the financial risk that retail insurers are exposed to), became the first in the industry to raise the possibility that climate change might present risks to insurers (Munich $\mathrm{Re}$ 1973). At the United Nations Conference on Environment and Development in June 1992 , insurers were encouraged to support climate change mitigation efforts. For example, Greenpeace's Jeremy Leggett, with a background in the oil industry, presented the argument that climate change challenged insurers' capacity to manage risk (Paterson 1999), and that mitigation offered the only viable way for insurers to manage climate risk. Given that insurers maintain substantial financial investments to support their capacity to pay out claims as necessary, Leggett urged insurers to divest from fossil fuel-intensive investments. Insurers, however, demurred.

\subsection{Why insurers have not acted already - the views from international political economy and organisational studies}

Paterson $(1999,2001)$ draws on international political economy (IPE) to explain why insurers did not respond favourably to Leggett and why they would in fact be unlikely to take strong action on climate change. Paterson (2001) argues that the industry has considered climate change a threat to itself that is manageable - in part because it considers itself as having at its disposal two apparent opportunities for limiting its own exposure to climate risk. The first 
strategy relates to system prediction and the potential for better prediction of extreme weather events over periods of 12-18 months, roughly congruent with standard reinsurance contract periods. This could allow reinsurers to increase premiums prospectively or limit exposures to large claims, for example by declining coverage in some years. This approach is problematic, even where technically possible. First, market expectations limit insurers' capacity to move in and out of markets at will—doing so undermines insurers' reputations for dependable risk management. Second, regulatory frameworks are also constraining: transferring and pooling risk is a key function in modern economies, and commercial insurance markets are heavily regulated to ensure ongoing access to insurance.

The second strategy relates to insurers' capacity to carry climate-implicated risks. For example, catastrophe bonds and other insurance-linked securities are financial instruments that allow climate risk to be shifted outside the insurance system and onto capital markets (Cabral 1999; Tynes 2000; Guy Carpenter \& Company LLC 2007). In the case of catastrophe bonds, a 'special purpose vehicle' (SPV) is created, which enters into a standard reinsurance contract with the insurer (or other risk carrier). Investors may then purchase bonds from the SPV, which invests the principal amount in low-risk money market instruments. Investors then earn premiums and interest on the investment. If no catastrophe occurs, the principal amount is repaid to investors. If a catastrophe occurs before the bond matures (usually after three years), however, the principal amount is used to cover the costs of the insurer and payments to investors may be reduced or even terminated (Tynes 2000; Entropics Asset Management AB, n.d.). This strategy, in short, provides a way to spread financial risks that are traditionally managed within the industry to the substantially enlarged pool that capital markets provide.

Herbstein (2015) complements the IPE account of insurer inaction with a perspective that draws on organisational studies (e.g., March 1991). Herbstein argues, with reference to underwriting, that organisations can be expected to fully exploit strategies with which they are 
familiar before exploring alternative approaches. For example, Herbstein identifies defensive underwriting, i.e., increasing premiums, tightening policy conditions and withdrawing cover, as a tried and tested approach that insurers will continue to employ prior to contemplating alternative approaches with which they have little or no prior experience (see also Herbstein et al. 2013). With reference to investment, Herbstein identifies a number of constraints on insurers' capacity and willingness to divest from fossil fuel-intensive investments, as Leggett had proposed in 1992. Constraints centre on the obligation of commercial insurers to continually maximise returns to shareholders and the intricacy of insurers' relationships with businesses in the fossil fuel sector: as insurers, as investors, and, in turn, as investees. As the size of the industry suggests, insurers have become located centrally and deeply in the fossil fuel-dependent global economy, and have reaped financial reward accordingly.

\subsection{What insurers have done}

Where insurers have responded to climate change, responses have been largely adaptive and 'weakly mitigative', as opposed to 'strongly mitigative'. Through a global (but not comprehensive) review, Mills (2007) identified 190 actors in the insurance industry taking 422 adaptation or weak mitigation actions - a figure that increased to 246 actors taking 643 actions in Mills' follow-up publication in 2009. Dlugolecki (2009, 17), however, describes this total as 'tiny' in the context of 'the tens of thousands of underwriting and intermediary firms in existence'. A more recent review identified 1148 actions by 378 entities in 2012 (Mills 2012), but Dlugolecki's point is well made.

The adaptive responses noted above, such as defensive underwriting and shifting financial risk onto capital markets, are made in the service of insurers' own capacity to adapt to climate change. Other responses are designed to support insurers' policyholders, who also seek to adapt to climate change. Some mitigate (i.e., reduce) losses, such as requiring more 
stringent building or land-use specifications. Others allow for some insureds' climate risks to be transferred, such as micro-insurance initiatives in low-income countries that allow smallscale farmers to mitigate catastrophic climate-implicated weather-related losses (see Phelan et al. 2011 for further detail).

A recent example of adaptive initiatives supported by insurers is the InsuResilience Global Partnership on Climate and Disaster Risk Finance and Insurance Solutions ('InsuResilience Global Partnership'), launched at the $23^{\text {rd }}$ Conference of the Parties (COP) under the United Nations Framework Convention on Climate Change (UNFCCC) in November 2017. The InsuResilience Global Partnership is a project of the UN Environment's Principles for Sustainable Insurance Initiative, and it has the support of a number of states (e.g., Germany, the UK, Ethiopia), insurers (e.g., Munich Re, Swiss Re, Allianz), and large civil society, UN, and other international organisations and institutions (e.g., the Nature Conservancy, UN Climate Resilience Initiative (A2R), and the World Bank).

The long-term viability of adaptation strategies is limited (Hallegatte 2009). Phelan and colleagues (2011) note that adaptive responses are likely to be counter-productive in the medium- and longer-term. To the extent that adaptive strategies are effective in facilitating expanding fossil fuel-based economic activity, these strategies serve to exacerbate the problem by accelerating climate change: what appears to be an adaptation may in fact prove to be a maladaptation (Barnett and O'Neill 2010) that ultimately increases vulnerability to climate risk for insurers, their policyholders, and all of humanity.

'Weakly mitigative' responses can be organised into three broad groups: (i) insurance products that support limited reductions in policyholders' emissions or that support other emission reduction initiatives; (ii) public policy-related research, lobbying and networking; and (iii) support for corporate carbon disclosure initiatives. Activities in all three groups are described as weakly mitigative because they deliver incidental or otherwise minor climate 
benefits, rather than significant-i.e., deep and rapid-cuts in greenhouse gas emissions necessary to seriously mitigate climate change.

Products that support emission reduction initiatives include those that align 'terms and conditions with risk-reducing behaviour' (Mills 2009), such as retail insurers offering pay-asyou-drive insurance, which results in risk being priced more accurately and reduced fuel consumption and emissions (Phelan et al. 2011). Another example is insurers addressing climate change liability implications, such as the possibility of policy-holding directors and officers facing damages claims by shareholders for not having disclosed climate risks. Mills (2009) cites Swiss Re, which includes climate change risks 'amongst the many criteria. . used to evaluate its exposures under corporate [directors and officers] policies' (27). Mills goes on to note that 'to our knowledge, Swiss Re has yet to actually decline a policy or apply exclusions based on climate risks alone', and that in the absence of any teeth to this approach ' $[\mathrm{t}] \mathrm{he}$ potentially positive effect of this activity is to stimulate the policyholders to focus on their climate-related exposures' (27).

A number of insurers have also made significant investments in renewable energy projects (Herbstein 2015, 36; Mills 2009, 44). For example, Munich Re in 2009 was involved in the founding of the ambitious Desertec Industrial Initiative (DII), which had the aim of developing a massive solar power park in the Sahara Desert to supply $15 \%$ of Europe's electricity by 2050 (Seager 2009). For various reasons, however, this project has not progressed further (Stonington 2012).

Public policy initiatives have been pursued in national contexts (see Phelan et al. 2011, 111-112), as well as in international contexts, such as climate negotiations. One notable recent public policy and lobbying initiative in which some insurers have played a role is the consideration of insurance during the negotiations under the UNFCCC. Insurance received attention when the Alliance of Small Island States (AOSIS), during the International 
Negotiating Committee sessions preceding the formation of the UNFCCC, called for the introduction of an International Insurance Pool to provide compensation to small island States and low-lying countries for loss and damage due to rising sea levels (Vanuatu: Draft Annex 1991). While this proposal was not accepted, both the UNFCCC and Kyoto Protocol include references to insurance (UNFCCC 1992, art. 8; Kyoto Protocol 1998, art. 3(14)). The issue of insurance has received more attention in subsequent years due to the increased importance of adaptation (Wenta, McGee and Phelan 2016, 37-38).

In 2013, in Warsaw, the $19^{\text {th }}$ COP under the UNFCCC established the Warsaw International Mechanism on Loss and Damage (Warsaw International Mechanism), which was subsequently included in the Paris Agreement (2015). The Paris Agreement calls on state Parties to 'enhance understanding, action and support, including through the Warsaw International Mechanism', and states that 'areas of cooperation and facilitation to enhance understanding, action and support may include ... comprehensive risk assessment and management ... [and] risk insurance facilities, climate risk pooling and other insurance solutions' (Paris Agreement 2015, art. 8(3)-(4)). There have been no concrete decisions on finance for this mechanism (Kreienkamp and Vanhala 2017, 9; Siddique and Darby 2017), however.

With regard to carbon disclosure initiatives, the most well-known voluntary initiative is the CDP (formerly known as the Carbon Disclosure Project), which allows investors, companies and cities to disclose their greenhouse gas reduction actions, with the aim of improving awareness and management, culminating in 'leadership' (CDP 2017)—perhaps through reducing emissions. In 2017, 1073 companies accounting for $12 \%$ of global emissions disclosed data to the CDP. While a number of insurance companies participated in the CDP in 2017, including American International Group (AIG), AXA, Allianz, Swiss Re and Munich Re, only two (both Japanese) were included in the A-list, which includes those businesses 
'leading on environmental performance' - assessed with reference to disclosure, awareness, management and leadership (CDP 2016, 56) — namely MS\&AD Insurance Group Holdings, Inc. and Sompo Holdings, Inc. (CDP 2017). One study showed that participants in the CDP experienced a number of benefits in addition to emission reductions, including increased transparency and efficiency and improved dialogue with stakeholders (Blanco, Caro and Corbett 2017). A further study found that carbon disclosure in the CDP was indicative of carbon performance and thus that CDP reports could be relied on by stakeholders to accurately reflect practice (Luo and Tang 2014).

\section{Forty years later: the first examples of strong mitigation?}

To be sure, insurers have a long history of engaging in mitigation of risks other than those related to climate change, such as establishing the first fire brigades, conducting early materials safety research, and proposing and lobbying for the introduction of safety standards that apply across all facets of human endeavours (Mills 2009, 67; Herbstein 2015, 12; O’Malley and Hutchinson 2007, 376-379). In the context of that history, and given the threat climate change presents, explanations for insurer inaction on climate change that date back almost twenty years (e.g., Paterson 1999, 2001) are sobering (South 2015) and remain compelling; and insurer behaviour in the period since then has remained largely unchanged. And yet, in very recent years, albeit forty years after Munich Re first raised questions about the potential impact of climate change on insurers, several insurers have announced 'divest and decline' decisions that, in our view, constitute strong mitigation action.

\subsection{Deciding to divest and decline coverage}

In recent years, a number of insurers have announced their decisions to divest coal assets and decline coverage of coal infrastructure. In 2014, KLP, a Norwegian insurer and pension fund 
manager, became one of the first insurers to divest, announcing its decision to divest from 27 coal companies (defined as those companies deriving at least $50 \%$ of their revenue from coalbased operations), and stating specifically that it 'decided to exclude coal companies from its investment portfolio because consumption of coal—at today's volumes — is not compatible with achievement of the two-degree target' (KLP 2014, 1-2). In 2015, KLP lowered the threshold to $30 \%$ of revenue from coal-based operations (KLP 2015). In 2015, AXA also divested from coal, announcing at the Climate Finance Day (part of COP21 in Paris) that it would 'divest from companies most exposed to coal-related activities for the assets managed internally' (De Castries 2015). More specifically, AXA stated that investment in mining companies and electric utilities that generate more than $50 \%$ of their revenue from coal production or the use of coal for their business 'should be avoided' (AXA Investment Managers 2017). Even more promising is that AXA has decided not to insure the companies in which it no longer invests. Two years later, in 2017, AXA announced that 'for reasons of consistency, the Group has also decided that the disengagement is applied to AXA's insurance operations', covering property and casualty insurance of the 'blacklisted companies' products, assets and liabilities' (AXA 2017).

In addition, just days before the UN climate change conference held in Paris in November 2015, Allianz announced its decision to divest 'equity stakes in coal-based business models by the end of March 2016' (Allianz 2015). 'Coal-based business models' were defined as mining companies earning at least $30 \%$ of their revenues from coal mining or electric utilities generating at least $30 \%$ of their electricity from coal (Allianz 2015).

While Munich Re has not made a public statement, it has reportedly decided to discontinue investing in companies earning at least $50 \%$ of their revenue from coal or generating $50 \%$ of their electricity from coal (Urgewald and Unfriend Coal 2017, 3-4). Another company, Swiss Re, also announced its decision to end investments in companies 
generating at least $30 \%$ of their revenue from coal mining and generating at least $30 \%$ of their power from coal (Swiss Re 2017, 27). In September 2017, yet another reinsurer, SCOR, declared that it would stop investing in coal companies earning $30 \%$ of their revenue from coal. Significantly, SCOR also stated that it would 'not issue insurance or facultative reinsurance [the reinsurance of individual, specific risks] that would specifically encourage new greenfield thermal coal mines or stand-alone lignite mines or plants' (SCOR 2017).

In 2017, Zurich Insurance Group announced a 'divest and decline' decision, stating that it would divest from equity holdings in companies earning more than half of their revenue from thermal coal mining and utilities generating more than half of their energy from coal. In addition it declared its intention to 'stop providing insurance or risk management services for new thermal coal mines or for potential new clients that derive more than half their revenue from mining thermal coal, and also for utility companies that generate more than half of their energy from coal' (Kuchinski 2017). At the same time, Swiss Re and Lloyd's stated that they would prepare new policies on coal in the ensuing months (Harrell and Bosshard 2017, 3). Based on these more recent actions, the divestment movement appears to be gaining momentum 'and may be approaching a tipping point' (Harrell and Bosshard 2017, 3).

While such decisions have been welcomed (e.g., 350.org 2015), they need to be considered closely. No divestment policies extend to funds managed on behalf of third parties. Furthermore, divestment from coal does not necessarily exclude divestment from other fossil fuels (Unfriend Coal 2017). Finally, Munich Re's policy disallows only investment in bonds, but still permits investment in equities (Urgewald and Unfriend Coal 2017, 3-4). This results in, amongst other things, the unsatisfactory situation where Munich Re holds bonds (but not equities) in Eskom (South Africa), which generates over 90\% of its electricity and earns more than $50 \%$ of its revenue from coal (Urgewald and Unfriend Coal 2017, 4-5). Turning from divestment to declining coverage, the policies of Swiss Re and Munich Re still permit these 
insurers to insure coal companies. The announcement of SCOR has also been criticised as it stops short of denying insurance to all coal projects (Unfriend Coal 2017).

Decisions to divest and decline are a clear step beyond earlier but limited apparent interest in directors' climate liabilities. Though welcome, insurers' strong mitigation actions to date are extremely limited in number and are constrained in their scope. The insurance industry has certainly not led efforts to mitigate climate change and attendant risks, as it was encouraged to do 25 years ago. Indeed, in 2016, the top 15 European insurers held US\$130.74 billion in fossil fuel companies (Simons and De Wilde 2017, 11-12), while the top 40 US insurers held US\$459 billion in fossil fuel companies in 2014 (McHale and Spivey 2016, 24). It is reasonable to expect that these recent decisions to divest and decline coverage will be observed by others within and beyond the industry. The potential for these actions to inspire further actions remains to be seen. The possible exposure of insurers to climate change liability (Bank of England PRA 2015) and concern over the potential for stranded assets (Caldecott et al. 2017) may also now begin to motivate insurers to take further actions.

\section{Conclusion: Insurance in the Anthropocene}

As Phelan and colleagues $(2011,125)$ note,

[t]he failure of the insurance system to respond appropriately to climate risk is consistent with broader societal inability to resolve the climate crisis. However, the insurance system's failure is notable to the extent that insurance is a primary risk governance instrument of industrialized economies and societies.

The loss of familiar Earth system stability does not necessarily mean the end of the insurance industry. Loss of familiar Earth system stability does, however, undermine the current linear basis for insurance, where history can be relied upon to serve as a guide to the future. A 
functioning insurance industry in a relatively unstable Earth system may or may not be recognisable in comparison to the insurance industry's current form, function and scale.

The divestment actions noted above are exceedingly limited in the context of a global industry comprising 'tens of thousands of underwriting and intermediary firms' (Dlugolecki $2009,17)$, but noteworthy because of the otherwise total lack of strongly mitigative action from insurers, and especially so given the compelling explanations for insurer inaction first proposed almost twenty years ago. The fact of these new actions raises questions about what insurers might need in order to realise a stronger 'fulcrum' (Shearing 2015) role and influence others to take further stronger mitigative action. One possibility is that the broader divestment movement has provided an example which insurers may now be able to follow. The divestment movement has included participation from universities, religious institutions, municipal governments and other public institutions, together with banks and other financial bodies upon which divestment activists have focussed their attention (Healy and Debski 2016; Healy and Barry 2017; Neslen 2017; Ayling and Gunningham 2017; Richardson 2017). Insurers have demonstrated an inability to lead on divestment, but may be able to follow divestment leaders in the finance sectors. As they do so they may, in turn, influence others. Looking ahead, as divestment is established more widely as an industry practice, it may be that insurers will increasingly be willing to decline cover for fossil fuel-intensive projects, infrastructure and businesses, consistent with the first tentative steps such as those noted above that some insurers have taken to engage with their clients' evolving climate liabilities.

Climate change presents a societal challenge of unprecedented spatial and temporal magnitude. Moving - in an orderly manner — beyond several centuries of the accelerating fossil fuel-based economic activity that causes climate change implies socio-economic challenges on an unprecedented scale and requires dramatic and rapid reductions in greenhouse emissions and protection of surviving carbon sinks such as forests. Insurers are not exclusively 
responsible for climate change, but neither is climate change a matter that can be resolved without effective participation of insurers, in the form of strongly mitigative action: we should expect nothing less from society's primary risk manager.

Insurers, of course, like all societal risk managers operate within the context of nodal assemblages of other auspices and providers of security (Burris et al. 2005). Criminology has traditionally concentrated its attention on responses to harm by professionals working within the criminal justice sub-assemblage (system). Within the context of the emerging 'harmscapes' that have begun to characterise the first quarter of the $21^{\text {st }}$ century-harms that extend from climate change through to cyber-insecurities - it has become increasingly clear that criminology should extend its gaze beyond its established boundaries to include institutions outside of criminal justice (Shearing 2015).

In this chapter we contributed to this shift of criminological attention beyond these boundaries. We did so by picking up a theoretical thread identified by thinkers like Ewald (1991), Ericson (see Ericson and Carriere 1994 and Ericson, Doyle and Barry 2003), and O’Malley (2017) who have identified commercial insurance as a key node within nodal security assemblages and networks. In doing so our hope is that others will also take up the long-standing invitation of criminologists such as Ditton (1979) and Hillyard and colleagues (2004) to move beyond criminology's established edges (see the volumes in Routledge's recent series Criminology at the Edge).

\section{References}

350.org. 2015. 'World's largest insurance company Allianz divests from coal.' 24 November. https://350.org/press-release/worlds-largest-insurance-company-allianz-divests-from-coal/.

Allen, Myles R. and David J. Frame. 2007. 'Call off the Quest.' Science 318 (5850): 582-583.

Allen, Myles R., David J. Frame, Chris Huntingford, Chris D. Jones, Jason A. Lowe, Malte Meinshausen and Nicolai Meinshausen. 2009. 'Warming Caused by Cumulative Carbon Emissions Towards the Trillionth Tonne.' Nature 458: 1163-1166. 
Allianz. 2015. 'Allianz statement on coal-based investments.' November. https://www.allianz.com/v_1448622620000/media/responsibility/Energy_Guideline PublicV ersion final.pdf.

AXA. 2017. 'AXA group policy on coal mining and coal-based energy.' http://www-axacom.cdn.axa-contento-118412.eu/www-axa-com\%2F803065f4-200e-4d5f-ae5e93a716b8e2d9 axa coal_policy_201704.pdf.

AXA Investment Managers. 2017. 'Coal policy.' April. https://www.axaim.com/documents/20195/607489/coal-policy-april-2017/545a5b09-8ce5-5467-de3576cda8654728.

Ayling, Julie and Neil Gunningham. 2017. 'Non-State Governance and Climate Policy: The Fossil Fuel Divestment Movement.' Climate Policy 17 (2): 131-149.

Bank of England PRA (Prudential Regulation Authority). 2017. The Impact of Climate Change on the UK Insurance Sector. http://www.bankofengland.co.uk/pra/Documents/supervision/activities/pradefra0915.pdf.

Barnett, Jon and Saffron J. O’Neill. 2010. 'Maladaptation.' Global Environmental Change 20 (2): 211-213.

Bayley David and Clifford Shearing. 2001. The New Structure of Policing: Description, Conceptualization, and Research Agenda. Washington, DC: US Department of Justice.

Beck, Ulrich. 1992. Risk Society: Towards a New Modernity. Los Angeles, CA: SAGE.

Blanco, Christian, Felipe Caro and Charles J. Corbett. 2017. 'An Inside Perspective on Carbon Disclosure.' Business Horizons 60 (5): 635-646.

Bosshard, Peter. 2017. Underwriting Climate Chaos: Insurance Companies, the Coal Industry and Climate Change. Surry Hills, Australia: Friends of the Earth France, Greenpeace Switzerland, Market Forces, Re:Common, Sierra Club, The Sunrise Project and Urgewald.

Burris, Scott, Peter Drahos and Clifford Shearing. 2005. 'Nodal governance.' Australian Journal of Legal Philosophy 30: 30-58.

Caldecott, Ben, Gerard Dericks, Alexander Pfeiffer and Pablo Astudillo. 2017. Stranded Assets: The Transition to a Low Carbon Economy - Overview for the Insurance Industry (Emerging Risk Report 2017: Innovation Series: Society and Security). Lloyd's. https://www.lloyds.com/news-and-insight/risk-insight/library/society-and-security/strandedassets.

Cabral, Warren. 1999. 'Securitisation out of the niche.' Global Reinsurance 8 (1). http://www.globalreinsurance.com.

CDP. 2016. Out of the Starting Blocks: Tracking Progress on Corporate Climate Action. https://b8f65cb373b1b7b15feb- 
c70d8ead6ced550b4d987d7c03fcdd1d.ssl.cf3.rackcdn.com/cms/reports/documents/000/001/2 28/original/CDP Climate Change Report 2016.pdf?1485276095.

CDP. 2017. 'CDP program scores.' https://www.cdp.net/en/scores-2017.

Chakrabarty, Dipesh. 2009. 'The Climate of History: Four Theses.' Critical Inquiry 35 (2):197-222.

Clark, Geoffrey. 1999. Betting on Lives: The Culture of Life Insurance in England, 1695-1775. Manchester: Manchester University Press.

De Castries, Henri. 2015. 'Climate change: It's no longer about whether, it's about when.' $A X A, 22$ May. https://www.axa.com/en/newsroom/news/about-whether-about-when.

Denenberg, Herbert S. 1963. 'The Legal Definition of Insurance: Insurance Principles in Practice.' The Journal of Insurance. 30 (3): 319-343.

Ditton, Jason. 1979. Controlology: Beyond the New Criminology. Michigan: MacMillan.

Dlugolecki, Andrew F. 2009. Coping with Climate Change: Risks and Opportunities for Insurers. London: Chartered Insurance Institute.

Entropics Asset Management AB. 'How cat bonds work.' http://en.entropics.se/catbonds/how-cat-bonds-work/.

Ericson, Richard, Aaron Doyle and Dean Barry. 2003. Insurance as Governance. Toronto, Buffalo, London: University of Toronto Press.

Ericson, Richard and Kevin Carriere. 1994. 'The Fragmentation of Criminology'. In The Futures of Criminology, edited by David Nelken, 89-109. London: SAGE.

Ewald, Francois. 1991. 'Insurance and Risk.' In The Foucault Effect: Studies in Governmentality, edited by Graham Burchell, Colin Gordon and Peter Miller, 197-210. Chicago: University of Chicago Press.

Fink, Amy. 2011. 'The origins of insurance' (Originally accessed at http://insurancecoveragemonitor.com/cgl/the-origins-of-insurance/.)

Gelbspan, Ross. 1998. The Heat is on: The Climate Crisis, the Cover-up, the Prescription. Reading: Perseus Books.

Griffin, Paul. 2017. The Carbon Majors Database: CDP Carbon Majors Report 2017. CDP. https://b8f65cb373b1b7b15febc70d8ead6ced550b4d987d7c03fcdd1d.ssl.cf3.rackcdn.com/cms/reports/documents/000/002/3 27/original/Carbon-Majors-Report-2017.pdf.

Guy Carpenter \& Company LLC. 2007. The Catastrophe Bond Market at Year-end 2006: Ripples into Waves. New York: Guy Carpenter \& Company LLC. 
Hall, Matthew and Stephen Farrall. 2013. 'The Criminogenic Consequence of Climate Change: Blurring the Boundaries between Offenders and Victims.' In Routledge International Handbook of Green Criminology, edited by Nigel South and Avi Brisman, 120-133. Abingdon: Routledge.

Hallegatte, Stéphane. 2009. 'Strategies to Adapt to an Uncertain Climate Change.' Global Environmental Change 19 (2): 240-247.

Harrell, Casey and Peter Bosshard. 2017. Insuring Coal No More: An Insurance Scorecard on Coal and Climate Change. Unfriend Coal. http://unfriendcoal.com/wpcontent/uploads/2017/11/UnfriendCoal-Insurance-Scorecard.pdf.

Harrington, Cameron and Clifford Shearing. 2017. Security in the Anthropocene: Reflections on Safety and Care. London and Bielefeld: Transcript Press.

Harvey, David. 2005. A Brief History of Neoliberalism. Oxford: Oxford University Press.

Healy, Noel and Jessica Debski. 2016. 'Fossil Fuel Divestment: Implications for the Future of Sustainability Discourse and Action within Higher Education.' Local Environment 22 (6): 699-724.

Healy, Noel and John Barry. 2017. 'Politicizing Energy Justice and Energy System Transitions: Fossil Fuel Divestment and a “Just Transition”.' Energy Policy 108: 451-459.

Hecht, Sean B. 2008. 'Climate Change and the Transformation of Risk: Insurance Matters.' UCLA Law Review 55 (6): 1559-1620.

Herbstein, Tom. 'Insurance and the Anthropocene: Like a Frog in Hot Water' (PhD thesis, University of Cape Town, 2015).

Herbstein, Tom, Jan Froestad, Deon Nel and Clifford Shearing. 2013. 'Insurance, ClimateRisk and the Barriers to Change.' In Business and Climate Change Governance: South Africa in Comparative Perspective, edited by Tanja A. Börzel and Ralph Hamann, 156172. London: Palgrave Macmillan.

Hillyard, Paddy, Cristina Pantazis, Steve Tombs, David Gordon and Daniel Doring. 2004. Beyond Criminology: Taking Harm Seriously. London: Pluto Press.

Holley, Cameron and Clifford Shearing. 2016. 'Policing and New Environmental Governance.' In SAGE Handbook of Global Policing, edited by Ben Bradford, Beatrice Jauregui, Ian Loader and Jonny Steinberg, 552-572. London: SAGE.

Holley, Cameron and Clifford Shearing. 2017. 'Thriving on a Pale Blue Dot: Criminology and the Anthropocene.' In Criminology and the Anthropocene, edited by Cameron Holley and Clifford Shearing. Abingdon: Routledge.

Holley, Cameron and Emma Lecavalier. 2017. 'Energy Governance, Energy Security and Environmental Sustainability: A Case Study from Hong Kong.' Energy Policy 108: 379-389. 
Holley, Cameron, Neil Gunningham and Clifford Shearing. 2012. The New Environmental Governance. Abingdon: Earthscan.

Honig, Maria, Samantha Petersen, Tom Herbstein, Saul Roux, Deon Nel and Clifford Shearing. 2015. 'A Conceptual Framework to Enable the Changes Required for a OnePlanet Future.’ Environmental Values 24 (5): 663-688.

IPCC (Intergovernmental Panel on Climate Change). 2013. 'Summary for Policymakers.' In Climate Change 2013: The Physical Science Basis. Contribution of Working Group I to the Fifth Assessment Report of the Intergovernmental Panel on Climate Change, edited by Thomas F. Stocker et al. Cambridge and New York: Cambridge University Press.

Johannsdottir, Lara, Brynhildur Davidsdottir, Michael E. Goodsite, and Snjolfur Olafsson. 2014. 'What is the Potential and Demonstrated Role for Non-Life Insurers in Fulfilling Climate Commitments? A Case of Nordic Insurers.' Environmental Science \& Policy 38: 87-106.

Kaufmann, Hans R. 1990. 'Storm damage insurance - quo vadis?' Swiss Re.

KLP. 2014. 'Decision to exclude from investments.' 1 December. http://english.klp.no/polopoly_fs/1.29228.1417436452!/menu/standard/file/Beslutning_Kull 261114\%20ENG.pdf.

KLP. 2015. '20 new companies excluded, 4 companies included.' http://english.klp.no/about$\mathrm{klp} / \mathrm{press}-\mathrm{room} / 20$-new-companies-excluded-4-companies-included-1.32410.

Kreienkamp, Julia and Lisa Vanhala. 2017. 'Climate change loss and damage.' Global Governance Institute. https://www.ucl.ac.uk/globalgovernance/downloads/policybriefs/policy-brief-loss-and-damage.

Kuchinski, Robert. 2017. 'Insurers can facilitate the transition to a low-carbon future.' Zurich Insurance Group. $13 \quad$ November. https://www.zurich.com/en/knowledge/articles/2017/11/insurers-can-facilitate-the-transitionto-a-low-carbon-future.

Kulp, Clarence A. and John W. Hall. 1968. Casualty Insurance. New York: The Ronald Press.

Kyoto Protocol (Kyoto Protocol to the United Nations Framework Convention on Climate Change) (1998) 37 ILM 22.

Leggett, Jeremy. 1993. Climate Change and the Insurance Industry: Solidarity among the Risk Community? Amsterdam: Greenpeace.

Lengwiler, Martin. 2003. 'Technologies of Trust: Actuarial Theory, Insurance Sciences, and the Establishment of the Welfare State in Germany and Switzerland around 1900.' Information and Organization 13 (2): 131-150.

Luo, Le and Qingliang Tang. 2014. 'Does Voluntary Carbon Disclosure Reflect Underlying Carbon Performance?' Journal of Contemporary Accounting \& Economics 10 (3): 191-205.

March, James G. 1991. 'Exploration and Exploitation in Organizational Learning.' Organization Science 2 (1): 71-87. 
McHale, Cynthia and Rowan Spivey. 2016. Assets or Liabilities? Fossil Fuel Investments of Leading U.S. Insurers. Boston: Ceres.

Meadows, Donella H. 1999. Leverage Points: Places to Intervene in a System. Hartland, VT: Chelsea Green Publishing.

Melone, Joseph J. 1964. 'Insurance: Transfer and Pooling.' In Risk and Insurance, edited by Herbert S. Denenberg, Robert Eilers, G. Wright Hoffman, Chester A. Kline, Joseph J. Melone and H. Wayne Snider, 141-151. Englewood Cliffs: Prentice-Hall.

Mills, Evan. 2007. 'Responding to Climate Change - the Insurance Industry Perspective.' In Climate Action, 100-103. Sustainable Development International and UNEP.

Mills, Evan. 2009. From Risk to Opportunity 2008: Insurer Responses to Climate Change. Ceres.

Mills, Evan. 2012. 'The Greening of Insurance.' Science 338 (6113): 1424-1425.

Munich Re. 1973. Flood Inundation. Munich: Munich Re.

Nel, Deon C., Clifford Shearing and Belinda Reyers. 2011. 'Insurers Could Help Address Climate Risks.' Nature 476: 33.

Neslen, Arthur. 2017. 'Catholic church to make record divestment from fossil fuels.' The Guardian, 3 October. https://www.theguardian.com/environment/2017/oct/03/catholicchurch-to-make-record-divestment-from-fossil-fuels.

O'Malley, Pat. 2017. 'Bentham in the Anthropocene: Imagining a Sustainable Criminal Justice. In Criminology and the Anthropocene, edited by Cameron Holley and Clifford Shearing. Abingdon: Routledge.

O'Malley, Pat and Steven Hutchinson. 2007. 'Reinventing Prevention: Why did "Crime Prevention” Develop so Late?' British Journal of Criminology 47 (3): 376-379.

Paterson, Matthew. 1999. 'Global Finance and Environmental Politics: The Insurance Industry and Climate Change.' IDS Bulletin 30 (3): 25-30.

Paterson, Matthew. 2001. 'Risky Business: Insurance Companies in Global Warming Politics.' Global Environmental Politics 1 (4): 18-42.

Petersen, Samantha, Clifford Shearing and Deon Nel. 2015. 'Sustainability Transitions: An Investigation of the Conditions under which Corporations are Likely to Reshape their Practices to Reverse Environmental Degradation.' Environmental Management and Sustainable Development 4 (1): 85-105.

Pfeffer, Irving and David R. Klock. 1974. Perspectives on Insurance. Englewood Cliffs: Prentice-Hall. 
Phelan, Liam, Ann Henderson-Sellers and Ros Taplin. 2010. 'Climate Change, Carbon Prices and Insurance Systems.' International Journal of Sustainable Development \& World Ecology 17 (2): 95-108.

Phelan, Liam, Ann Henderson-Sellers and Ros Taplin. 2011. 'Mitigation of the Earth's Economy: A Viable Strategy for Insurance Systems.' In The Economic, Social and Political Elements of Climate Change, edited by Walter Leal Filho, 81-98. Berlin: Springer-Verlag.

Phelan, Liam, Ros Taplin, Ann Henderson-Sellers, and Glenn Albrecht. 2011. 'Ecological Viability or Liability? Insurance System Responses to Climate Risk.' Environmental Policy and Governance 21 (2): 112-130.

Pinkse, Jonatan and Ans Kolk. 2009. International Business and Global Climate Change. London and New York: Routledge.

Richardson, Benjamin J. 2017. 'Divesting from Climate Change: The Road to Influence.' Law and Policy 39 (4): 325-348.

Rockström, Johan, Will Steffen, Kevin Noone, Åsa Persson, F. Stuart Chapin III, Eric F. Lambin, Timothy M. Lenton, et al. 2009. 'A Safe Operating Space for Humanity.' Nature 461: $472-475$.

Roe, Gerhard R. and Marcia B. Baker. 2007. 'Why is Climate Sensitivity so Unpredictable?' Science 318 (5850): 629-632.

Sachs, Wolfgang, Manfred Linz, Reinhard Loske and Wuppertal Institute for Climate Environment and Energy. 1998. Greening the North: A Post-Industrial Blueprint for Ecology and Equity. London: Zed Books.

Schneider, Stephen H. 2004. 'Abrupt Non-Linear Climate Change, Irreversibility and Surprise.' Global Environmental Change 14 (3): 245-258.

SCOR. 2017. 'Press release No 23: SCOR announces further environmental sustainability initiatives.' $6 \quad$ September. $\quad$ https://www.scor.com/sites/default/files/23 coal disengagement veng.pdf.

Seager, Ashley. 2009. 'Solar power from Sahara a step closer.' The Guardian, 1 November. https://www.theguardian.com/business/2009/nov/01/solar-power-sahara-europe-desertec.

Shearing, Clifford. 2015. 'Criminology and the Anthropocene.' Criminology \& Criminal Justice 15 (3): 255-269.

Shearing, Clifford, Cameron Harrington and Cameron Holley. Forthcoming. 'Security and the Anthropocene in Law, International Relations and Criminology.' Annual Review of Law and Social Science.

Siddique, Abu and Megan Darby. 'Climate insurance website to be launched at Bonn talks.' Climate Home News, 10 November. http://www.climatechangenews.com/2017/11/10/climateinsurance-website-launched-bonn-talks/. 
Simons, Margreet and Joeri de Wilde. 2017. The Involvement of the European Insurance Groups in the Fossil Fuels Sector (A report for the Sunrise Project). Amsterdam: Profundo.

South, Nigel. 2015. 'Anticipating the Anthropocene and Greening Criminology.' Criminology \& Criminal Justice 15 (3): 270-276.

Stonington, Joel. 2012. 'Desertec's promise of solar power for Europe fades.' Spiegel Online, 13 November. http://www.spiegel.de/international/europe/the-desertec-solar-energy-projecthas-run-into-trouble-a-867077.html.

Swiss Re. 2017. Responsible Investments: Shaping the Future of Investing. http://media.swissre.com/documents/ZRH-17-11623-

P1 Responsible\%20Investments WEB.PDF.

Swiss Re Institute. 2017. World Insurance in 2016: The China Growth Engine Steams Ahead. Sigma No. 3/2017.

Trenerry, Charles F. 1926. Origin and Early History of Insurance. London: P.S. King \& Son.

Tynes, Johannes S. 2000. 'Catastrophe Risk Securitization.' Journal of Insurance Regulation 19 (1): 3-28.

UNFCCC (United Nations Framework Convention on Climate Change) (1992) 31 ILM 849.

Unfriend Coal. 2017. 'Climate and coal policies of leading global insurers - briefing papers.' 3 August. http://unfriendcoal.com/2017/08/03/climate-and-coal-policies-of-leading-globalinsurers-briefing-papers/.

Urgewald and Unfriend Coal. 2017. 'Munich Re needs to take bold action on climate change and coal.' 2 August. http://unfriendcoal.com/wp-content/uploads/2017/08/Briefing-paperMunich-Re-0817-E.pdf.

UNEP-FI (UNEP Finance Initiative). 2009. The Global State of Sustainable Insurance Understanding and Integrating Environmental, Social and Governance Factors in Insurance. Geneva.

UNEP-FI (UNEP Finance Initiative). 2011. Insurance in a Changing Risk Landscape: Local Lessons from the Southern Cape of South Africa. Geneva.

Vanuatu: Draft Annex Relating to Article 23 (Insurance) for Inclusion in the Revised Single Text on Elements Relating to Mechanisms (A/AC.237/WG.II/Misc.13) submitted by the Cochairmen of Working Group II. 17 December 1991. UN Doc A/AC.237/WG.II/CRP.8.

Walters, Reece. 2010. 'Toxic Atmospheres Air Pollution, Trade and the Politics of Regulation.' Critical Criminology 18: 307 - 323.

Wenta, Joseph, Jeffrey McGee and Liam Phelan. 2016. 'Can a Regional Insurance Mechanism Enhance Resilience to Slow Onset Impacts of Climate Change?' University of Tasmania Law Review 35 (2): 23-57. 
Wuebbles, Donald J. et al. 2017. 'Executive summary.' In Climate Science Special Report: Fourth National Climate Assessment, Volume I, edited by Donald J. Wuebbles et al. Washington DC: U.S. Global Change Research Program. 